\title{
Rancang Bangun Antena Semi Circular Dengan Teknik GDS (Defect Ground Structure) untuk Meningkatkan Bandwidth Antena Pada Aplikasi WIFI
}

\author{
Trushero Kharisma Claudiani $^{1}$, Koesmarijanto ${ }^{2}$, Hendro Darmono ${ }^{3}$ \\ 1,3 Program Studi Jaringan Telekomunikasi Digital, \\ Jurusan Teknik Elektro, Politeknik Negeri Malang, Indonesia \\ 2 Program Studi Teknik Telekomunikasi, \\ Jurusan Teknik Elektro, Politeknik Negeri Malang, Indonesia \\ 1'trushero.diani@gmail.comd, ${ }^{2}$ koesmarijanto@polinema.ac.id, ${ }^{3}$ hendro.darmono@polinema.ac.id
}

\begin{abstract}
The increasing need for the amount of data sent and the speed of data transmission via wireless technology has resulted in high interest in devices with wide bandwidth. Improving antenna design is one way to increase Bandwidth. The antenna is designed in such a way as to get the antenna parameters that are effective, one of which is to increase the antenna bandwidth. The techniques used to improve microstrip antenna parameters is the Defect Ground Structure (DGS) technique. The methods used are calculation, simulation and measurement. The results of the semicircular array microstrip antenna without DGS, the return loss parameter value is $-13.7 \mathrm{~dB}$ and the VSWR value is 1.518 and has a gain of $1.3 \mathrm{dBi}$ at a frequency of $2455 \mathrm{MHz}$. This antenna has the form of a bidirectional radiation pattern. The antenna bandwidth obtained is $14 \mathrm{MHz}$. The result of the semicircular array microstrip antenna with DGS, the return loss parameter value is $-14.4 \mathrm{~dB}$ and the VSWR value is 1.469 and has a gain of $2.8 \mathrm{dBi}$ at a frequency of 2455 MHz. This antenna has the form of a directional radiation pattern. The antenna bandwidth obtained is 10 MHz. The conclusion of this research is that the semicircular array microstrip antenna without DGS has a smaller bandwidth than the semicircular array microstrip antenna with DGS, which is a difference of $3.5 \mathrm{MHz}$.
\end{abstract}

Keywords - Antenna, Microstrip, Semicircular, DGS, Wi-Fi, Bandwidth.

Abstrak-Kebutuhan yang semakin meningkat akan banyaknya data yang dikirim dan kecepatan pengiriman data melalui teknologi wireless mengakibatkan tingginya minat terhadap perangkat dengan Bandwidth lebar. Memperbaiki desain antena adalah salah satu cara untuk meningkatkan Bandwidth. Antena didesain sedemikian rupa agar mendapatkan parameter antena yang bernilai efektif salah satunya untuk meningkatkan bandwidth antena. Salah satu teknik yang digunakan untuk memperbaiki parameter antena miksrostrip yaitu teknik Defect Ground Structure (DGS) dengan metode yang digunakan adalah perhitungan, simulasi dan pengujian. Hasil pengujian antena mikrostrip array semicircular tanpa DGS diperoleh nilai parameter return loss sebesar -13,7 dB dan nilai VSWR sebesar 1,518 serta memiliki gain bernilai 1,3 dBi pada frekuensi $2455 \mathrm{MHz}$. Antena ini memiliki bentuk pola radiasi bidirectional. Bandwidth antena yang diperoleh sebesar 14 MHz. Hasil pengujian antena mikrostrip array semicircular dengan DGS diperoleh nilai parameter return loss sebesar -14,4 dB dan nilai VSWR sebesar 1,469 serta memiliki gain bernilai 2,8 dBi pada frekuensi $2455 \mathrm{MHz}$. Antena ini memiliki bentuk pola radiasi directional. Bandwidth antena yang diperoleh sebesar 10 MHz. Kesimpulan dari penelitian ini adalah antena mikrostrip array semicircular tanpa DGS mempunyai bandwidth yang lebih kecil dibandingkan dengan antena mikrostrip array semicircular dengan DGS yaitu dengan selisih sebesar 3,5 MHz.

Kata kunci- Antena, mikrostrip, semicircular, DGS, Wi-Fi, bandwidth.

\section{PENDAHULUAN}

Salah satu contoh alat yang menggunakan teknologi transmisi wireless yaitu Wi-Fi. Wi-Fi yang merupakan singkatan dari Wireless Fidelity adalah perangkat yang digunakan untuk membentuk jaringan Wireless Local Area Network (WLAN). Wi-Fi dapat digunakan untuk mentransfer data, mengakses internet dan juga dapat membentuk jaringan tanpa adanya kabel (wireless). Wi-Fi Adanya teknologi transmisi wireless tidaklah lepas dari sebuah komponen yang fungsinya penting yaitu antenna[1].

Wi-Fi merupakan teknologi yang populer saat ini, memiliki spesifikasi yaitu Wi-Fi 802.11b, Wi-Fi 802.11a, Wi-Fi 8012.11g, dan Wi-Fi 802.11n. WiFi bekerja pada frekuensi 2,4 GHZ dan $5 \mathrm{GHz}$, memiliki paling tidak 11 - 13 channel dengan lebar tiap channel sebesar $1 \mathrm{MHz}$. Rata - rata Wi-Fi memiliki kecepatan data dari 11 Mbps sampai dengan $100 \mathrm{Mbps[2].}$ Kebutuhan yang semakin meningkat akan banyaknya data yang dikirim dan kecepatan pengiriman data mengakibatkan tingginya minat terhadap perangkat dengan bandwidth lebar. Memperbaiki desain antena adalah salah satu cara untuk meningkatkan bandwidth antenna[3].

Antena merupakan suatu alat yang berfungsi untuk mentransmisikan gelombang radio. Antena didesain sedemikian rupa agar mendapatkan antena dengan parameter yang bernilai efektif. Salah satu teknik yang digunakan untuk memperbaiki parameter antena miksrostrip yaitu teknik DGS (Defect Ground Structure). Diharapkan melalui perancangan antena dengan teknik DGS dapat meningkatkan bandwidth 
terutama bandwidth pada antena. Teknik DGS merupakan suatu teknik yang memberikan suatu pola atau bentuk di bagian ground pada antena.

\section{METODE}

A. Perancangan Antena

1) Perancangan Elemen Peradiasi

Antenna yang direncanakan memiliki frekuensi resonansi sebesar $2,442 \mathrm{GHz}$. Nilai panjang gelombang di riuang bebas $\lambda_{0}=125 \mathrm{~mm}$ dan untuk panjang gelombang transmisi antenna $\lambda_{d}=58,925 \mathrm{~mm}$. Menggunakan persamaan dibawah ini untuk mendapatkan nilai jari - jari efektif patch [1].

$a_{e}=\sqrt{\frac{L_{e f f} \times W_{e f f}}{\pi}}$

\section{Keterangan}

$a_{e} \quad=$ jari - jari efektif patch

$L_{\text {eff }}=$ panjang efektif rectangular patch

$W_{\text {eff }}=$ lebar efektif rectangular patch

Sehingga didapatkan nilai jari-jari efektif untuk patch semicircular $a_{e}=29.388 \mathrm{~mm}$.

2) Perancangan Saluran Transmisi

Menentukan nilai impedansi dari setiap saluran. Untuk impedansi saluran Zin menggunakan persamaan[2].

$Z_{i n}=60 \times \frac{\lambda_{d}}{w}$

Keterangan

Zin = impedansi input

$\lambda_{d} \quad=$ panjang gelombang transimi antenna

$\mathrm{w}=$ diameter dari patch semicircular

Setelah menentukan impedansi dari setiap saluran transmisi maka selanjutnya menghitung lebar saluran transmisi dengan menggunakan persamaan berikut [2]

$W=\frac{120 \pi}{\sqrt{\varepsilon_{r}}} \times \frac{h}{Z o}$

\section{Keterangan}

$\mathrm{W}=$ lebar saluran pencatu

$\mathrm{H} \quad=$ lebar substrat

$\varepsilon_{r} \quad=$ konstanta dielektrik

Zo = nilai impedansi saluran

Untuk menghitung panjang saluran transformer digunakan persamaan berikut [3]

$L_{z}=\frac{1}{4} \lambda_{d}$

\section{A. Hasil Pengujian return Loss}

\section{HASIL DAN PEMBAHASAN}

1) Hasil Pengujian return Loss dan VSWR antenna microstrip array semicircular tanpa DGS

Hasil pengujian Return Loss dan VSWR antena mikrostrip array patch semicircular tanpa DGS. Nilai level antena yang diuji dapat dilihat pada Gambar 1

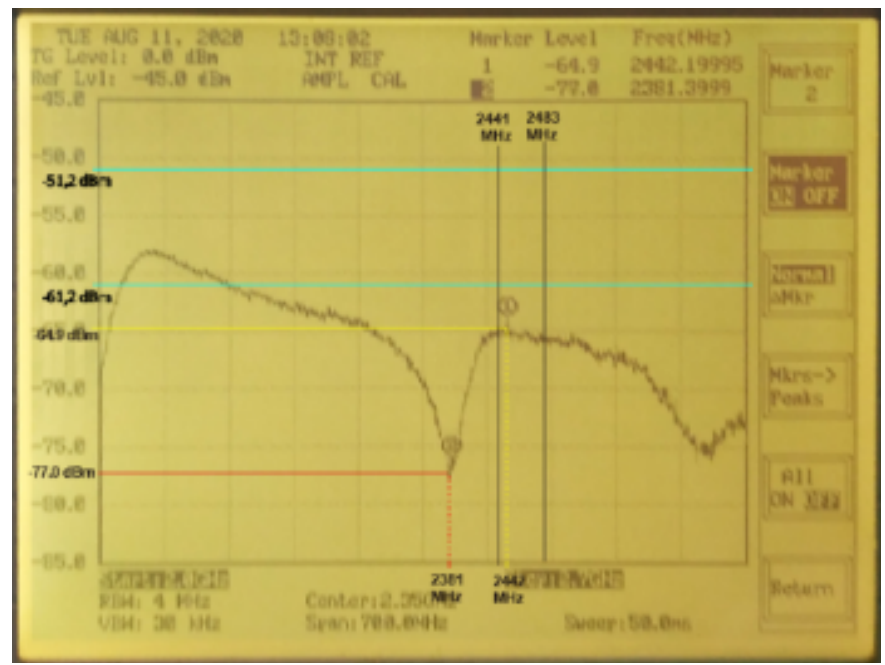

Gambar 1. Hasil pengujian Return Loss antena mikrostrip array semicircular tanpa DGS

Nilai level daya antena yang telah diperoleh digunakan untuk menghitung nilai Return Loss. Dengan persamaan berikut:

$\mathrm{R}_{\mathrm{L}}=$ Level $_{\mathrm{AUT}}-$ Level $_{\text {reff }}-\mathrm{ATT}_{\mathrm{DC}}$

Keterangan :

$\mathrm{R}_{\mathrm{L}} \quad$ : Return Loss

Level $_{\mathrm{AUT}}$ : level daya dari antena yang diuji

Level $_{\text {reff }}:$ level daya referensi

ATT $_{\mathrm{DC}} \quad$ : attenuasi dari directional copler

$\mathrm{R}_{\mathrm{L}}=$ Level $_{\mathrm{AUT}}-$ Level $_{\text {reff }}-\mathrm{ATT}_{\mathrm{DC}}$

$\mathrm{R}_{\mathrm{L}}=-77,0 \mathrm{dBm}-(-31,4 \mathrm{dBm})-(-20)=-25,6 \mathrm{~dB}$

Nilai Return Loss akan digunakan untuk mencari nilai koefisien pantul yang nantinya nilai koefisien pantul digunakan untuk menghitung nilai VSWR.

$$
\mathrm{R}_{\mathrm{L}}=20 \log |\Gamma|
$$

$$
\begin{aligned}
& |\Gamma|=10^{\frac{-25.6}{20}}=0.052 \\
& V S W R=\frac{1+|\Gamma|}{1-|\Gamma|} \\
& V S W R=\frac{1+0,052}{1-0,052}=1,109
\end{aligned}
$$

Menurut Gambar 1 pada marker 1 dengan frekuensi $2442 \mathrm{MHz}$ didapatkan nilai level antena yaitu $-64,9 \mathrm{dBm}$ 
dengan nilai level referensi -31,2 dan pada marker 2 dengan frekuensi $2381 \mathrm{MHz}$ didapatkan nilai level antena yaitu 77,0 dBm dengan level referensi $-31,4 \mathrm{dBm}$, untuk atenuasi directional coupler sebesar -20 .

TABEL I

HASIL PERHITUNGAN NILAI RETURN LOSS DAN VSWR

\begin{tabular}{cccc}
\hline Marker & Frekuensi & Return Loss & VSWR \\
\hline 1 & $2442 \mathrm{MHz}$ & $-13,7 \mathrm{~dB}$ & 1,518 \\
\hline 2 & $2381 \mathrm{MHz}$ & $-25,6 \mathrm{~dB}$ & 1,109 \\
\hline
\end{tabular}

2) Hasil Pengujian Return Loss dan VSWR antenna Mikrostrip Array Semicircular dengan DGS

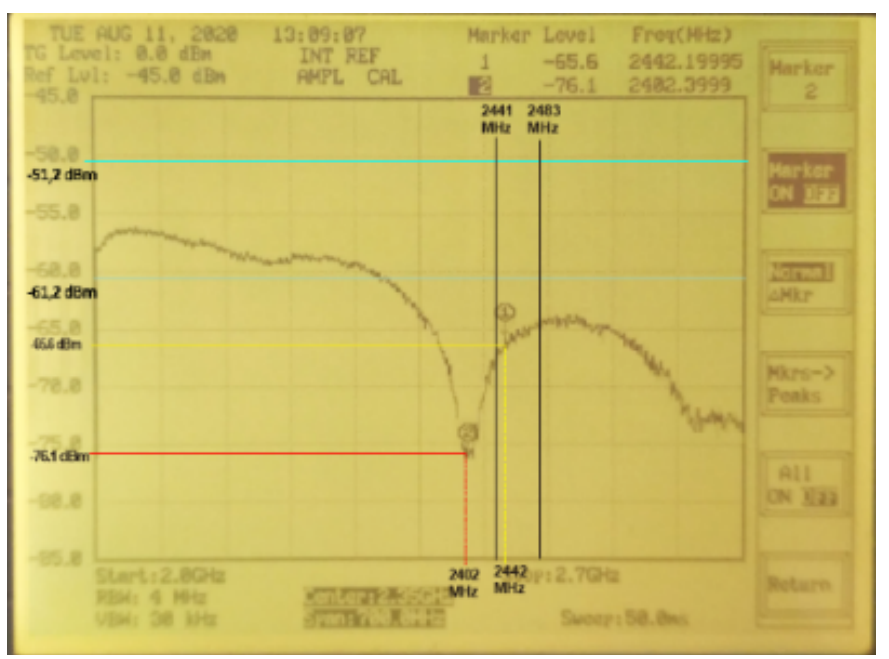

Gambar 2. Hasil pengujian Return Loss antena mikrostrip array semicircular dengan DGS

Nilai Return Loss didapatkan dengan menggunakan persamaan berikut

$\mathrm{R}_{\mathrm{L}}=$ Level $_{\mathrm{AUT}}-$ Level $_{\text {reff }}-\mathrm{ATT}_{\mathrm{DC}}$

$\mathrm{R}_{\mathrm{L}}=-76,1 \mathrm{dBm}-(-31,8 \mathrm{dBm})-(-20)$

$$
=-24,6 \mathrm{~dB}
$$

Nilai Return Loss akan digunakan untuk mencari nilai koefisien pantul yang nantinya nilai koefisien pantul digunakan untuk menghitung nilai $V S W R$.

$\mathrm{R}_{\mathrm{L}}=20 \log |\Gamma|$

$|\Gamma|=10^{\frac{-24.2}{20}}=0,061$

$V S W R=\frac{1+|\Gamma|}{1-|\Gamma|}$

$V S W R=\frac{1+0,061}{1-0,061}=1,12$

Menurut Gambar 2 pada marker 1 dengan frekuensi $2442 \mathrm{MHz}$ didapatkan nilai level daya antena yaitu $-65,6$ $\mathrm{dBm}$ dengan nilai level referensi -31,2 dan pada marker 2 dengan frekuensi $2402 \mathrm{MHz}$ didapatkan nilai level antena yaitu $-76,1 \mathrm{dBm}$ dengan level referensi $-31,8 \mathrm{dBm}$, untuk atenuasi directional coupler sebesar -20
TABEL II

\begin{tabular}{cccc}
\multicolumn{4}{c}{ HASIL PERHITUNGAN NILAI RETURN LOSS DAN VSWR } \\
\hline Marker & Frekuensi & Return Loss & VSWR \\
\hline 1 & $2442 \mathrm{MHz}$ & $-14,4 \mathrm{~dB}$ & 1,469 \\
\hline 2 & $2402 \mathrm{MHz}$ & $-24,2 \mathrm{~dB}$ & 1,12 \\
\hline
\end{tabular}

\section{B. Hasil Pengujian Gain}

Pengujian gain dari antena mikrostrip array semicircular tanpa DGS dan antena mikrostrip array semicircular dengan DGS dapat dilihat pada tabel berikut.

TABEL III

Hasil Pengujian Gain ANTENNA Under Test

\begin{tabular}{ccc}
\hline $\begin{array}{c}\text { Frekuensi } \\
(\mathbf{M H z})\end{array}$ & $\begin{array}{c}\text { Gain antena } \\
\text { mikrostrip array } \\
\text { semicircular tanpa } \\
\text { DGS (dBi) }\end{array}$ & $\begin{array}{c}\text { Gain antena mikrostrip } \\
\text { array semicircular } \\
\text { dengan DGS (dBi) }\end{array}$ \\
\hline 2,435 & $-4,7$ & $-11,0$ \\
\hline 2,440 & $-0,4$ & $-15,2$ \\
\hline 2,442 & $-12,2$ & $-13,9$ \\
\hline 2,445 & $-12,0$ & $-12,4$ \\
\hline 2,450 & $-3,2$ & $-4,7$ \\
\hline 2,455 & 1,3 & 2,8 \\
\hline 2,460 & 0,4 & 1,3 \\
\hline 2,465 & $-3,2$ & 1,4 \\
\hline 2,470 & $-7,2$ & $-9,4$ \\
\hline 2,475 & $-5,9$ & $-9,2$ \\
\hline
\end{tabular}

Hasil pengujian gain dari antena mikrostrip array semicircular tanpa DGS yang didapatkan direpresentasikan pada grafik berikut ini

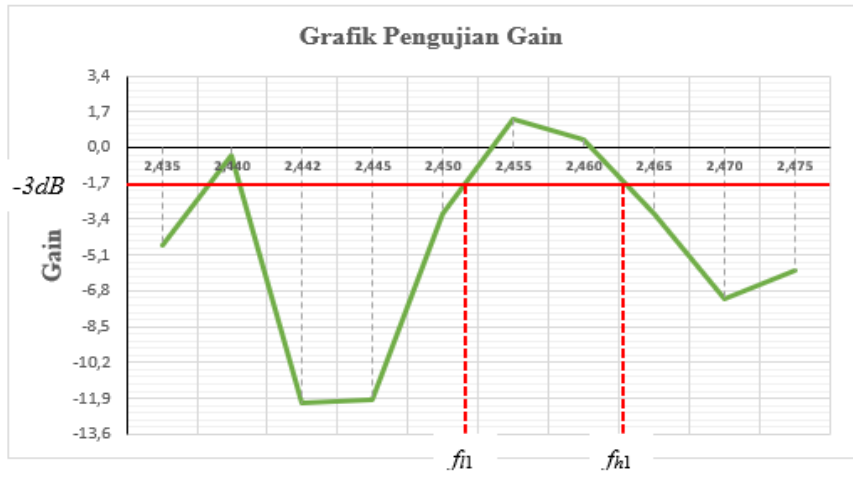

Gambar 3. Grafik pengujian gain untuk antena mikrostrip array semicircular tanpa DGS

Nilai gain yang bernilai positif berada pada frekuensi 2455 $\mathrm{MHz}$ dan $2460 \mathrm{MHz}$. Besar frekuensi tersebut tidak termasuk dari frekuensi resonan desain antena. Sehingga dikatakan antena ini tidak resonan. Nilai gain yang paling besar berada pada frekuensi $2445 \mathrm{MHz}$ sebesar 1,3 dBi. Bandwidth yang didapatkan sebagai berikut

$B W=f_{h 1}-f_{l 1}$

$B W=2,465-2,452$

$B W=13 \mathrm{MHz}$ 


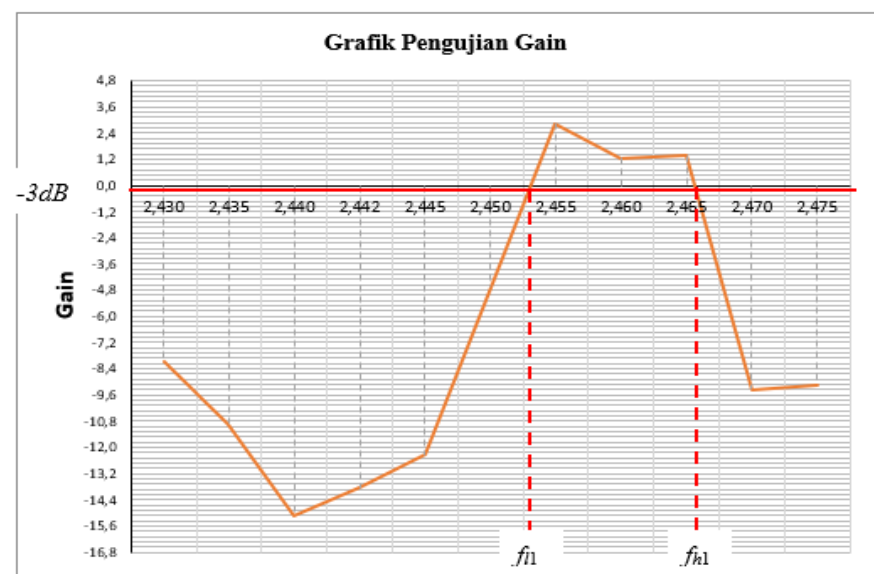

Gambar 4. Grafik pengujian gain untuk antena mikrostrip array semicircular tanpa DGS

Nilai gain yang bernilai positif berada pada frekuensi 2455 dan $2460 \mathrm{MHz}$. Besar frekuensi tersebut tidak termasuk dari frekuensi resonan desain antena. Sehingga dikatakan antena ini tidak resonan. Nilai gain yang paling besar berada pada frekuensi $2445 \mathrm{MHz}$ yaitu sebesar 2,8 dBi. Bandwidth yang didapatkan sebagai berikut.

$B W=f_{h 1}-f_{l 1}$

$B W=2467-2457$

$B W=10 \mathrm{MHz}$

\section{Hasil Pengujian Pola Radiasi}

Pengujian pola radiasi dari kedua AUT dapat dilihat pada tabel berikut

TABEL IV

HASIL PENGUJIAN POLA RADIASI

\begin{tabular}{|c|c|c|c|c|}
\hline \multirow{3}{*}{ Sudut } & \multicolumn{4}{|c|}{$2,442 \mathrm{MHz}$} \\
\hline & \multicolumn{2}{|c|}{$\begin{array}{l}\text { Antena mikrostrip array } \\
\text { semicircular tanpa DGS }\end{array}$} & \multicolumn{2}{|c|}{$\begin{array}{l}\text { Antena mikrostrip array } \\
\text { semicircular dengan DGS }\end{array}$} \\
\hline & $\begin{array}{c}\text { Level } \\
\text { daya } \\
\text { (dBm) }\end{array}$ & $\begin{array}{l}\text { Normalisari } \\
\text { (dB) }\end{array}$ & $\begin{array}{c}\text { Level } \\
\text { daya } \\
(\mathrm{dBm})\end{array}$ & $\begin{array}{l}\text { Normalisai } \\
\text { (dB) }\end{array}$ \\
\hline 0 & $-75,2$ & $-5,9$ & $-74,2$ & $-9,8$ \\
\hline 10 & $-72,8$ & $-3,5$ & $-74,8$ & $-10,4$ \\
\hline 20 & $-69,3$ & 0 & $-72,7$ & $-8,3$ \\
\hline 30 & $-71,2$ & $-1,9$ & -69 & $-4,6$ \\
\hline 40 & $-69,8$ & $-0,5$ & -72 & $-7,6$ \\
\hline 50 & $-72,2$ & $-2,9$ & $-76,6$ & $-12,2$ \\
\hline 60 & $-75,2$ & $-5,9$ & $-69,6$ & $-5,2$ \\
\hline 70 & -75 & $-5,7$ & $-72,9$ & $-8,5$ \\
\hline 80 & -75 & $-5,7$ & $-76,7$ & $-12,3$ \\
\hline 90 & -73 & $-3,7$ & $-72,5$ & $-8,1$ \\
\hline 100 & $-72,1$ & $-2,8$ & -73 & $-8,6$ \\
\hline 110 & $-73,3$ & -4 & $-71,9$ & $-7,5$ \\
\hline 120 & -75 & $-5,7$ & $-74,9$ & $-10,5$ \\
\hline 130 & $-75,8$ & $-6,5$ & $-74,5$ & $-10,1$ \\
\hline 140 & -75 & $-5,7$ & $-72,4$ & -8 \\
\hline 150 & $-74,1$ & $-4,8$ & $-71,1$ & $-6,7$ \\
\hline 160 & -76 & $-6,7$ & $-69,5$ & $-5,1$ \\
\hline 170 & -75 & $-5,7$ & -71 & $-6,6$ \\
\hline 180 & $-76,3$ & -7 & -77 & $-12,6$ \\
\hline 190 & $-76,6$ & $-7,3$ & $-76,9$ & $-12,5$ \\
\hline 200 & $-76,7$ & $-7,4$ & -75 & $-10,6$ \\
\hline 210 & $-75,8$ & $-6,5$ & $-69,1$ & $-4,7$ \\
\hline 220 & $-75,7$ & $-6,4$ & $-72,1$ & $-7,7$ \\
\hline
\end{tabular}

\begin{tabular}{ccccc}
\hline \multirow{3}{*}{ Sudut } & \multicolumn{4}{c}{$\mathbf{2 , 4 4 2} \mathbf{M H z}$} \\
\cline { 2 - 5 } & $\begin{array}{l}\text { Antena mikrostrip array } \\
\text { semicircular tanpa DGS }\end{array}$ & $\begin{array}{c}\text { Antena mikrostrip array } \\
\text { semicircular dengan DGS }\end{array}$ \\
\cline { 2 - 5 } & $\begin{array}{l}\text { Level } \\
\text { daya } \\
(\mathbf{d B m})\end{array}$ & $\begin{array}{c}\text { Normalisari } \\
\mathbf{( d B )}\end{array}$ & $\begin{array}{c}\text { Level } \\
\text { daya } \\
\text { (dBm) }\end{array}$ & $\begin{array}{c}\text { Normalisai } \\
\text { (dB) }\end{array}$ \\
\hline 230 & $-74,8$ & $-5,5$ & $-67,7$ & $-3,3$ \\
\hline 240 & $-76,1$ & $-6,8$ & $-69,8$ & $-5,4$ \\
\hline 250 & -73 & $-3,7$ & $-72,8$ & $-8,4$ \\
\hline 260 & $-73,1$ & $-3,8$ & -75 & $-10,6$ \\
\hline 270 & $-75,4$ & $-6,1$ & -77 & $-12,6$ \\
\hline 280 & $-74,2$ & $-4,9$ & -72 & $-7,6$ \\
\hline 290 & $-75,4$ & $-6,1$ & $-71,7$ & $-7,3$ \\
\hline 300 & $-73,2$ & $-3,9$ & $-65,7$ & $-1,3$ \\
\hline 310 & $-70,3$ & -1 & $-64,9$ & $-0,5$ \\
\hline 320 & $-69,4$ & $-0,1$ & $-64,8$ & $-0,4$ \\
\hline 330 & $-72,5$ & $-3,2$ & $-64,4$ & 0 \\
\hline 340 & $-74,2$ & $-4,9$ & $-67,4$ & -3 \\
\hline 350 & $-74,3$ & -5 & $-73,2$ & $-8,8$ \\
\hline 360 & $-74,3$ & -5 & $-75,3$ & $-10,9$ \\
\hline
\end{tabular}

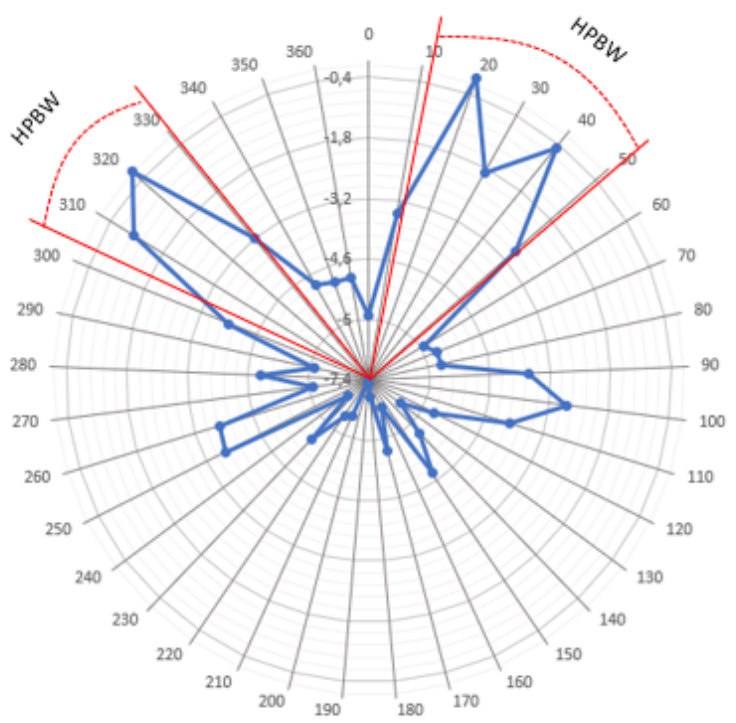

Gambar 5. Diagram polar pola radiasi untuk antena mikrostrip array semicircular tanpa DGS

Nilai HPBW direpresentasikan dengan melakukan pengurangan nilai sudut tertinggi dengan sudut terendah yang menghubungkan titik pusat lingkaran dengan titik daya bernilai sebesar $-3 \mathrm{~dB}$. Nilai HPBW berdasarkan diagram polar dapat diketahui yaitu sebagai berikut:

\section{HPBW 1}

HPBW $1=330^{\circ}-303^{\circ}$

HPBW $1=27^{\circ}$

HPBW 2

HPBW $2=51^{\circ}-12^{\circ}$

HPBW $2=39^{\circ}$

HPBW total

HPBW total $=27^{\circ}+39^{\circ}=66^{\circ}$

Pola radiasi yang ditampilkan pada diagram polar antena mikrostrip array semicircular dengan DGS yaitu bidirectional. 


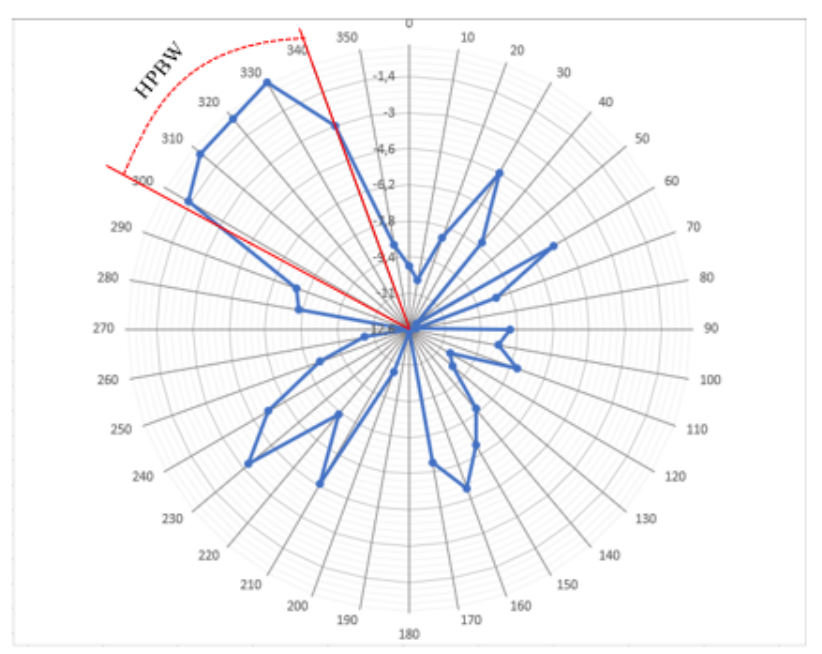

Gambar 6. Diagram polar pola radiasi untuk antena mikrostrip array semicircular dengan DGS

Nilai HPBW direpresentasikan dengan melakukan pengurangan nilai sudut tertinggi dengan sudut terendah yang menghubungkan titik pusat lingkaran dengan titik daya bernilai sebesar $-3 \mathrm{~dB}$. Nilai HPBW berdasarkan diagram polar dapat diketahui yaitu sebagai berikut:

$\mathrm{HPBW}=341^{\circ}-298^{\circ}$
$\mathrm{HPBW}=41^{\circ}$

Pola radiasi yang ditampilkan pada diagram polar antena mikrostrip array semicircular dengan DGS yaitu directional.

\section{IV.KESIMPULAN}

\section{A. Kesimpulan}

Pengujian antena mikrostrip array semicircular tanpa DGS didapatkan nilai return loss untuk frekuensi $2381 \mathrm{MHz}$ sebesar $-25,6 \mathrm{~dB}$; VSWR sebesar 1,109; nilai Gain terbesar sebesar 1,3 $\mathrm{dBi}$; dengan pola radiasi bidirectional; nilai HPBW 1 sebesar $27^{\circ}$ dan nilai HPBW 2 sebesar $39^{\circ}$.

Pengujian antena mikrostrip array semicircular tanpa DGS didapatkan nilai return loss untuk frekuensi $2402 \mathrm{MHz}$ sebesar $-24,2 \mathrm{~dB}$; VSWR sebesar 1,12; nilai Gain terbesar sebesar 2,8 $\mathrm{dBi}$; dengan pola radiasi directional dan nilai HPBW sebesar $41^{\circ}$.

Pengujian bandwidth didapatkan untuk antena mikrostrip array semicircular tanpa DGS memiliki bandwidth sebesar 10,5 MHz dan untuk antena mikrostrip array semicircular dengan DGS memiliki nilai bandwidth sebesar $14 \mathrm{MHz}$. Hasil perbandingan parameter Bandwidth untuk kedua antena under test didapatkan bahwa antena mikrostrip array semicircular dengan DGS memiliki nilai bandwidth yang lebih baik dibandingkan dengan antena mikrostrip array semicircular tanpa DGS dengan selesih nilai bandwidth sebesar 3,5 MHz.

B. Saran

Sebelum dilakukannya fabrikasi hendaknya melakukan pengecekan terlebih dahulu parameter pada simulasi apakah sudah sesuai dengan yang dibutuhkan
Melakukan survey bahan yang digunakan untuk fabrikasi antena. Mulai dari ukuran ketebalan substrat dan tembaga, serta nilai permitivitas dielektrik dari pcb yang digunakan karena nantinya akan mempengaruhi hasil pengujian.

Tidak disarankan untuk menggunakan antena mikrostrip dengan patch semicircular pada kebutuhan frekuensi tinggi dan kebutuhan gain tinggi.

Sebaiknya dilakukan percobaan dengan beberapa tipe pencatuan tidak hanya pencatuan mikrostrip feedline.

\section{REFERENSI}

[1] Bocheng, Z., "Novel Broadband Microstrip Antenna", vol. 2. 1995.

[2] Johnson, Richard C, “Antenna Engineering handbook $3^{\text {rd }}$ edition", McGraw-Hill International, New York, 1993.

[3] Sharma. S, "Impedance Mathcing techniques for Microstrip path Antenna", Indian J. Sci. techno, 10, pp 116, 2017. 